\title{
PREVALENCE OF SYPHILIS IN PREGNANCY AND RELATED SOCIOECONOMIC FACTORS IN THE 2015 PELOTAS BIRTH COHORT.
}

Mariangela Freitas da Silveira(1), Gregore Mielke (1), Andrea Damaso Bertoldi (1), Marlos Rodrigues Domingues (2)

(1) Post Graduate Program in Epidemiology, Federal University of Pelotas; (2) Faculty of Physical Education, Federal University of Pelotas

\section{BACKGROUND:}

America's region is engaged in eliminating maternal to child transmission of syphilis, but in 2015 , a growing rate of 1.7 cases per 1,000 live births was observed, related to Brazil's cases ( $85 \%$ of the region's cases) ${ }^{1}$. This increase was attributed by Brazilian Ministry of Health to increased testing, penicillin shortages, and lack of adequate treatment at primary care clinics ${ }^{1}$. This study aimed to examine prevalence of maternal syphilis and its associated factors among participants of the 2015 Pelotas (Brazil) Birth Cohort Study.

\section{METHODS:}

All hospital-delivered children born from mothers that live in the urban area of Pelotas in 2015 were included in the study. Information on maternal health status, antenatal care and socio-demographic characteristics were collected. Prevalence of gestational syphilis, crude and adjusted odds ratio (OR) and their $95 \%$ confidence intervals $(95 \% \mathrm{Cl})$ were calculated according to maternal age, schooling and skin color, marital status and family income.

\section{RESULTS:}

4275 children from 4219 mothers were enrolled in the study. Most of the mothers were between 20-30 years old $(47.4 \%), 14.6 \%$ teenagers; $65.1 \%$ had 9 or more years of schooling and nearly $86.0 \%$ were married/had a living in partner. Prevalence of gestational syphilis was $2.1 \%$. The coverage of one syphilis test was almost $100 \%$. In the adjusted analyses it was found a higher risk of syphilis among teenagers mothers (OR 2.41; 95\% $\mathrm{Cl} 1.2-4.86$ ), those with 4 or less years of schooling (OR 4.25; 95\% $\mathrm{Cl} 1.75-10.33)$ and with brown/black skin (OR1.90; $95 \% \mathrm{Cl}$ 1.22-2.96). (Table 1)

\section{CONCLUSIONS:}

Prevalence of gestational syphilis for 2015 in our study was higher than national prevalence (1.1\%) but in accordance with Rio Grande do Sul state (2.0\%), where Pelotas is located. Findings from this study suggest that services for syphilis are included in prenatal care, but, to achieve congenital syphilis elimination, efforts must be made to reach higher risk pregnant women with good quality prenatal care.
Prevalence of maternal syphilis according to socioeconomic variables, 2015 Pelotas Birth Cohort.

\begin{tabular}{|c|c|c|c|c|}
\hline \multirow[b]{2}{*}{ Variable } & \multirow[b]{2}{*}{$\mathbf{N}(\%)$} & \multicolumn{3}{|c|}{ Syphilis } \\
\hline & & Prevalence & Crude OR (IC95\%) & $\begin{array}{l}\text { Adjusted OR* } \\
\text { (IC95\%) }\end{array}$ \\
\hline \multicolumn{5}{|l|}{ Age (years) } \\
\hline$\geq 30$ & $1,598(38.1)$ & 0.8 & 1.00 & 1.00 \\
\hline $20-39$ & $1,992(47.4)$ & 2.6 & $3.20(1.74-5.91)$ & $2.55(1.37-4.73)$ \\
\hline$<20$ & $614(14.6)$ & 3.9 & $4.96(2.51-9.80)$ & $2.41(1.20-4.86)$ \\
\hline \multicolumn{5}{|l|}{ Schooling } \\
\hline $12+$ & $1,305(30.9)$ & 0.7 & 1.00 & 1.00 \\
\hline $9-11$ & $1,442(34.2)$ & 1.2 & $1.72(0.76-3.88)$ & $1.14(0.49-2.66)$ \\
\hline $5-8$ & $1,084(25.7)$ & 3.6 & $5.38(2.59-11.16)$ & $2.52(1.10-5.78)$ \\
\hline $0-4$ & $387(9.2)$ & 6.1 & $9.27(4.25-20.21)$ & $4.25(1.75-10.33)$ \\
\hline \multicolumn{5}{|l|}{ Income } \\
\hline $3^{\circ}$ tercile (richest) & $1,390(33.0)$ & 1.0 & 1.00 & 1.00 \\
\hline $2^{\circ}$ tercile & $1,325(31.4)$ & 1.4 & $1.36(0.67-2.73)$ & $0.76(0.37-1.57)$ \\
\hline $1^{\circ}$ tercile (poorest) & $1,502(35.6)$ & 3.8 & $3.82(2.11-6.90)$ & $1.33(0.68-2.60)$ \\
\hline \multicolumn{5}{|c|}{\begin{tabular}{|l|l} 
Marital status & \\
\end{tabular}} \\
\hline $\begin{array}{l}\text { Married/living } \\
\text { partner }\end{array}$ & $3,619(85.8)$ & 1.8 & 1.00 & 1.00 \\
\hline Single & $599(14.2)$ & 4.0 & $2.33(1.44-3.75)$ & $1.48(0.90-2.42)$ \\
\hline \multicolumn{5}{|l|}{ Skin color } \\
\hline White & $2,982(70.8)$ & 1.3 & 1.00 & 1.00 \\
\hline Other & $1,230(29.2)$ & 3.9 & 2.99 (1.96-1.58) & $1.90(1.22-2.96)$ \\
\hline
\end{tabular}

*adjusted for all the variables on the table*

1 Elimination of mother-to-child transmission of HIV and syphilis in the Americas. Update 2016. Washington, D.C.: PAHO; 2017.

This study aimed to examine maternal syphilis in the 2015 Pelotas (Brazil) Birth Cohort. Prevalence was 2.1\%, higher than national one, being bigger among teenagers, and those less schooled, and with brown/black skin. Findings suggest that, to achieve congenital syphilis elimination, efforts must be made to reach higher risk women. 